\title{
Retrospective investigation of enteric illnesses in pet animals
}

\author{
Hiam Ramadan Elnageh ${ }^{1}$, Murad Ali Hiblu ${ }^{2}$, Abojala Elhashmi Ammar ${ }^{3}$, Yousef M Abouzeed ${ }^{4}$, \\ Emadeddin Abdulkarim ${ }^{5}$, Ali Alareid ${ }^{6}$, Mohamed Omar Ahmed ${ }^{7}$ \\ 1,3,5,6 Alhelal Alazraq Veterinary Clinic, Libya \\ 1,4,7 Department of Microbiology and Parasitology, Faculty of Veterinary Medicine, University of Tripoli, Libya \\ ${ }^{2}$ Department of Internal Medicine, Faculty of Veterinary Medicine, University of Tripoli, Libya
}

\begin{tabular}{l} 
Article Info \\
\hline Article history: \\
Received Jun 19, 2019 \\
Revised Jul 20, 2019 \\
Accepted Aug 21, 2019 \\
\hline
\end{tabular}

\section{Keywords:}

Enteric bacteria

Libya

Pet animals

Retrospective analysis

Veterinary records

\begin{abstract}
Recording and analysis of data are key elements to understand the epidemiology of various infectious and zoonotic diseases such as enteric pathogens and conditions. In this study, the clinical records of Alhelal Alazraq veterinary clinic in Tripoli were investigated for enteric diseases and illnesses in cats and dogs during the period of 2010-2015. The diagnostic and therapeutic guidelines within the Libyan veterinary system were also assessed and discussed based on the retrieved information and records. A total of 859 cases representing $528(61 \%)$ from cats and 331 (39\%) from dogs were retrieved and analysed using descriptive analysis. The cases were originated from five major areas from the center of Tripoli and the surrounding areas. Of these, 835/859 (97\%) cases adopted antimicrobial based therapies and administered various antibiotic classes mainly and respectively using penicillin $(652 ; 78 \%)$ and trimethoprim-sulfamethoxazole $(229 ; 27 \%)$. The current study is the first retrospective investigation that analysed clinical and medical information from a major veterinary clinic in Libya. Diagnostic and therapeutic guidelines in the veterinary settings in Libya should be carefully reviewed and addressed. Retrospective studies and research programmes that monitor and investigate the occurrences of zoonotic and emerging pathogens particularly in relation to antimicrobial resistance are warranted in the Libyan health and medical systems.
\end{abstract}

Copyright (c) 2019 Institute of Advanced Engineering and Science. All rights reserved.

\section{Corresponding Author:}

Mohamed Omar Ahmed,

Department of Microbiology and Parasitology,

Faculty of Veterinary Medicine,

University of Tripoli, P.O.BOX 13662, Tripoli, Libya.

Email: a.mo@live.com

\section{INTRODUCTION}

Data and clinical information are key elements to understand the occurrence and epidemiology of various communicable and infectious diseases [1-2]. Proper reporting, history and information records, and data analysis are essential elements to prevent and control infectious-zoonotic diseases and strengthen research programmes particularly in the underdeveloped regions [3]. Such data and information on the role of animals as a potential source of emerging agents (e.g., nosocomial, foodborne, and zoonotic bacterial organisms) are very limited from the developing regions such as Africa. Of these, the enteric bacterial pathogens which are reportedly emerging in the globe as a serious public health concern [4-5] are not well defined nor understood mainly from pets and companion animals particularly from the underdeveloped countries such as Libya. 
Companion and pet animals can harbour zoonotic pathogens of serious health and medical concern spreading virulent and antibiotic resistance determinants [6-7]. Of these, the gastrointestinal (GI) enteric bacteria (e.g., Salmonella, E.coli 0157 and Campylobacter) are documented as a serious global concern responsible for serious diarrheagenic illnesses and foodborne outbreaks including in Libya [4-5]. These pathogens have been largely associated with food producing animals and more recently with household pets, and responsible for the acquisition and spreading of multidrug resistant bacteria [7-8]. However, pet's population are not estimated, and their distribution and the associated health risks are not well understood particularly in the developing regions.

Retrospective and scientometric information from Libya as well as underdeveloped countries that focus on humans and animal medicine are absent [1]. Such scientific approaches are very useful, particularly in countries where research and surveillance programmes are difficult to be carried due to various regional and economic factors. Such studies can cover up large gaps of needed and important information which can offer better grounds for effective and prospective research programmes. In this investigation, we sought to investigate and analyse the records of Alhelal Alazraq veterinary clinic in Tripoli for cases of enteritis and enteric like illnesses only in pet animals during the period of January 2010-December 2015. The Alhelal Alazraq clinic is a major state healthcare setting situated in Tripoli centre and largely receive cases of cats and dogs of various clinical conditions mainly of enteric and diarrhoeal illnesses. The diagnostic and therapeutic procedure of this major veterinary clinic will be also discussed.

\section{RESEARCH METHOD}

The Alhelal Alazraq clinic is located in Alzawia street in Tripoli, providing various medical services to owners of various animal species, mainly household pets (i.e. cats and dogs). The diagnosis at the clinic is mainly based on clinical symptoms, case-history information and limited laboratory tests. The records of the clinic were investigated for cases of cats and dogs that were diagnosed with enteritis and/or enteritis (diarrhoeal) like-illnesses and treated at the clinic during the five years period (January 2010-December 2015). Depending on the available information, the retrieved cases were introduced and organized in an Excel spreadsheet adopting the following main criteria: type of pet, name of the owner, date of admission, street and area of origin (only Tripoli and the suburban areas), diagnosis and details about the treatment with focus on the administered antimicrobial drugs. Street and area of origins of all cases were organized into five categorized areas (A-E). Descriptive statistical analysis was performed on the collected Excel data.

\section{RESULTS AND ANALYSIS}

A total of 859 cases were retrieved representing $528(61 \%)$ cats and 331 dogs (39\%) with a frequency annual rate range between 7-24\% as shown in Figures 1 dan 2. Of these only 483/859 (56\%) were originated from various streets within and around Tripoli and were organized into five designated areas (area A-E) as shown in Table 1 and Figure 3 (Map). Of the total cases, 835/859 (97\%) were administered antimicrobial drugs mainly and respectively to penicillin $(652 ; 78 \%)$, trimethoprim/sulfamethoxazole (TMP/SMX) (229; 27\%), tylosin $(25 ; 3 \%)$, gentamycin $(7 ; 1 \%)$ and spectinomycin $0.6 \%$ as describes in Figure 4.

Investigations and retro-analytic studies that analyze clinical and medical information from healthcare settings particularly of animal and veterinary medicine are very rare in Libya [1]. The presented and interesting data in this article revealed important information on the demographic distribution of pet animals as well as the basis of the diagnostic adopted procedures in the veterinary health system in Libya. In this study, the admitted cases of cats overlapped those from dogs which would suggest that the former is likely the most common household pet in Tripoli. This could be attributed to the location of the clinic which is situated in the city centre and to the fact that dogs and in contrast to cats, are frequently kept in large houses and farms, and usually used for security as well as breeding purposes. However, our results clearly showed that cats are the most likely adopted house-pet in Tripoli city. 


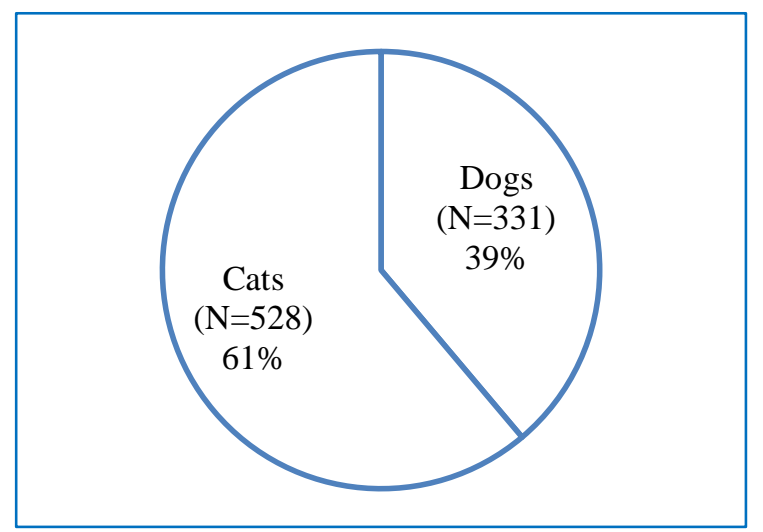

Figure 1. Proportion of animal species among the investigated cases

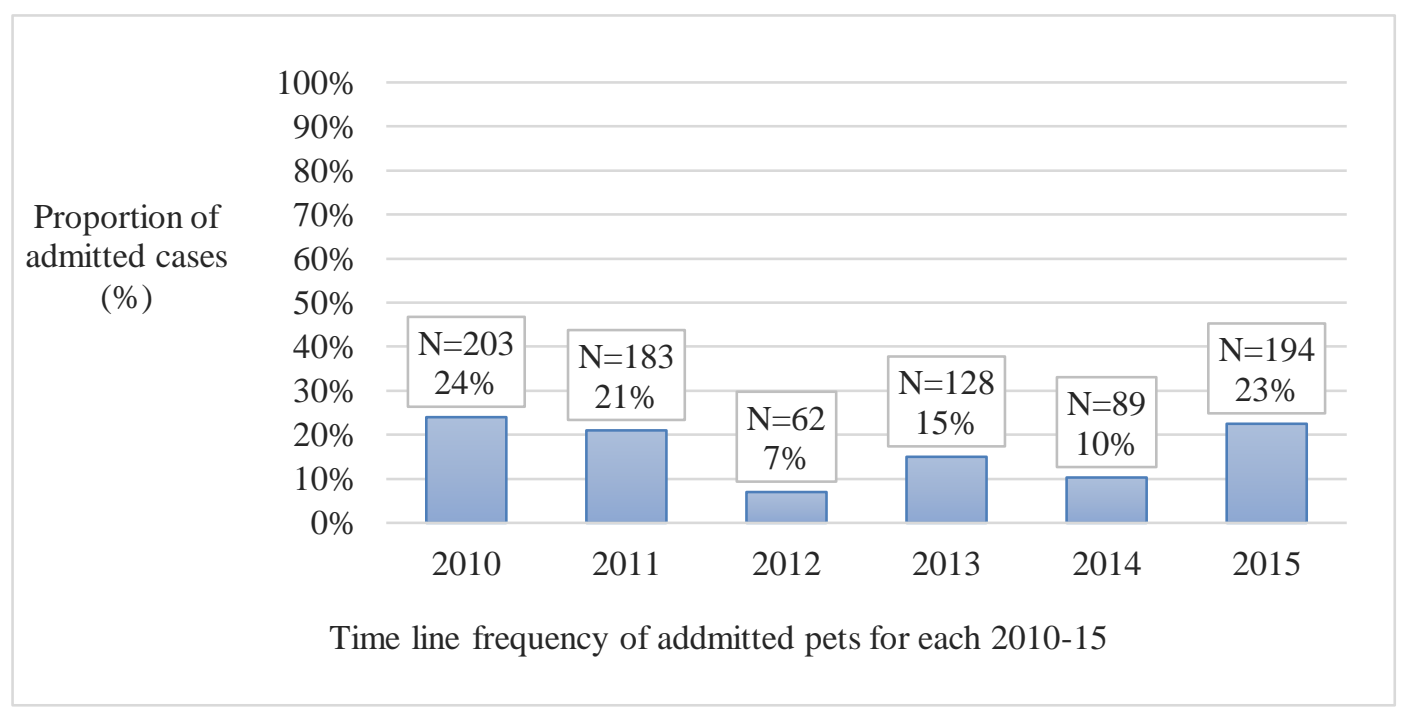

Figure 2. Proportion and frequency of clinical cases during 2010-2015

Table 1. Source and distribution of cases within and around Tripoli city

\begin{tabular}{|c|c|c|}
\hline $\begin{array}{l}\text { Assigned } \\
\text { Area }\end{array}$ & $\begin{array}{c}\text { Number of admitted } \\
\text { cases }\end{array}$ & Original streets and areas from Tripoli and the surrounding areas (Arabic Language) \\
\hline A & 103 & $\begin{array}{c}\text { Shara Mizran, Shara Almgarief, Aldahra, Shara Alnasr, Tariq Almatar, Gharghour, Bab } \\
\text { Alaziziyyah, Alfelah, Bin Ashour, Shara Aldol, Tariq Assur, Shara Alzawiyah, Shara } \\
\text { Alsreem, Shara Aljamahurriyah }\end{array}$ \\
\hline B & 319 & $\begin{array}{l}\text { Abu Salim, Alhadba, Ain Zara, Alfornaj, Khallet Alforjan, Salah Aldeen, Hay Demsheq, } \\
\text { Gergarish, Hay Alandalus, Ghot Alshal, Aldrabi, Keshlaf, Gaddah, Alhay Aleslami, Gorje }\end{array}$ \\
\hline $\mathrm{C}$ & 21 & Souq Aljum'aa, Alnofleen, Zanatah, Arada, $11^{\text {th }}$ yulio, Alhashan, Tajoura, Alsabaa \\
\hline $\mathrm{D}$ & 9 & Alswani, Qaser Bin Ghashir \\
\hline $\mathrm{E}$ & 31 & Janzur, Alsarraj, Angela \\
\hline
\end{tabular}

In this study, the clinical and laboratory protocols that have been used to diagnose the potential causative agents of the treated cases were not fully indicated or recorded. Nowadays, such process is frequently followed in veterinary clinics as a normal standard guideline for diagnosis and before treatment. Generally, the clinical-laboratory process used in the Libyan veterinary clinics to aid diagnosis and treatment is inadequate and largely unclear (personal experience and communications). This is mainly attributed to insufficient laboratory equipment, lack of a national reference-lab and shortage of professional personnel. Furthermore, in this investigation the clinical basis that have been adopted for differential diagnosis between 
the bacterial and viral enteritic cases were not clear nor fully recorded. Therefore, the basis of antibiotic based-therapies were not clear.



Figure 3. (Map) distribution of cases in Tripoli City and the surrounding areas

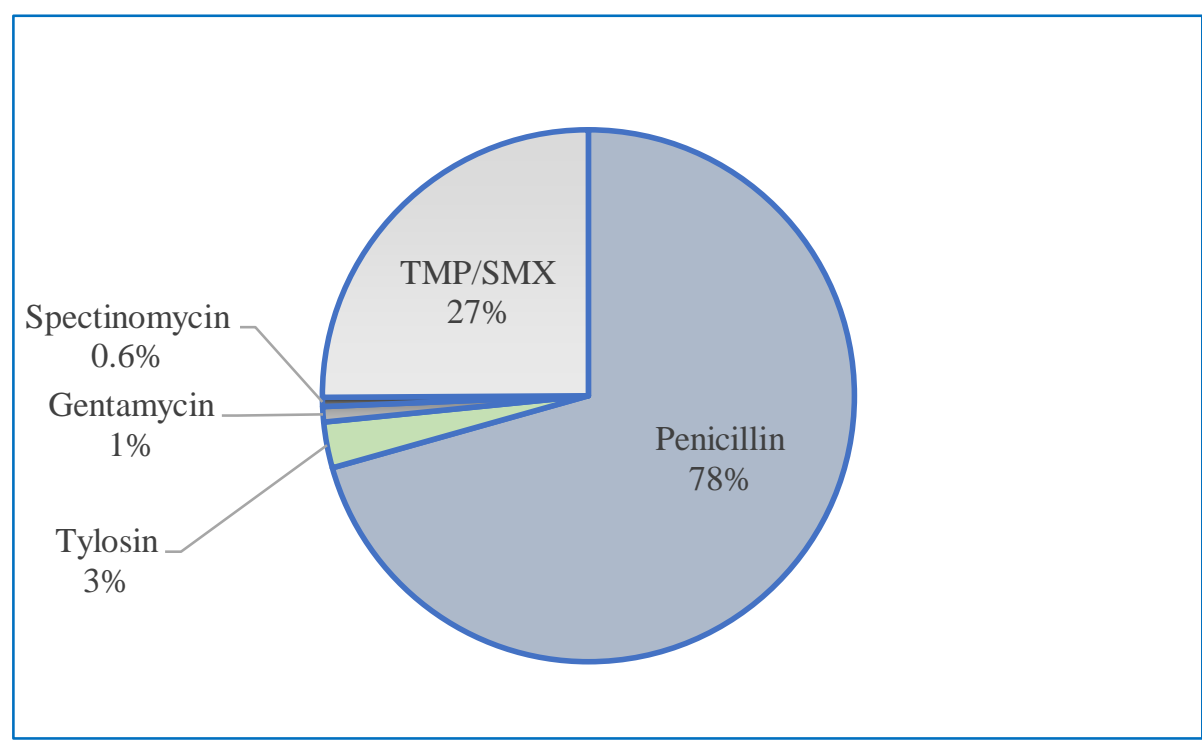

Figure 4. Rates and proportion of prescribed antimicrobial classes

The important revealed finding of this investigation is the administration of antibiotics without a proper laboratory and bacteriological methods (e.g. antimicrobial susceptibility tests). This is a very serious medical and health concern considering the recent documentation of the alarming emergence of antimicrobial resistance in various bacterial organisms in Libya [9-11]. In addition, studies that investigate the role of animals as a source of zoonotic and antimicrobial resistance organisms are rare in/from Libya however, 
recent evidences have revealed the role of various animal species as a source of emerging bacterial and antimicrobial resistant pathogens such as staphylococci, Salmonella and E.coli 0157 [6, 12]. This is a critical gap in the biomedical and research information which are extremely necessary to understand and control the current serious and emerging problem of antimicrobial resistance in humans in Libya.

Zoonotic and foodborne pathogens are a global concern with the capacity to spread rapidly causing significant morbidity, increasing mortality and socioeconomic consequences particularly in the developing countries [5, 13-14]. The emergence and geographic variability of such critical bacterial pathogens and the associated multidrug resistant phenotypes (e.g. VRE, MRSA and ESBLs) are evidently linked with the use of antimicrobial agents in both human and animals (e.g. fluoroquinolones, glycopeptides and cephalosporines) [15-16]. Unfortunately, the reservoir and the occurrence of such strains remain largely unclear in animals, particularly in the developing regions.

Household pets are widely kept for various purposes and with various level of caring. Pets are frequently kept in/within homes for company, leisure, work or social support and can carry and be colonized with a variety of zoonotic and pathogenic bacteria including multidrug resistant organisms [17-18]. Pet owners are often unaware and underestimate the health risks that their pets might pose as a source of infectious and zoonotic diseases, including antimicrobial resistance [19]. Bacterial zoonosis of pet origins are largely neglected compared to other animals such as food producing animals. Such zoonotic threats are a serious concern for the community, such as young, old, pregnant or immunocompromised which may acquire the infection due to the non-hygiene closeness with their pet and companion animals [17].

\section{CONCLUSION}

To the best of our knowledge, this is the first study that has investigated and analysed the records of a major veterinary clinic in Libya providing novel and important information of medical and health concern on pet animals. Public health and veterinary authorities should provide adequate support for veterinary clinics to upgrade their laboratories and develop the professional skills of their personnel to aid clinical and diagnostic guidelines. The spread of antimicrobial resistance of animal origin are a global concern, and the local authorities should take urgent actions to control the emergence and spread of these critical and threatening pathogens. Antimicrobial stewardship particularly toward animal medicine is a very important step in controlling the spread of infectious agents including antimicrobial resistance.

Healthcare and academic researchers should undertake more scientometrics and retrospective analysis which can offer important information and data for prospective research programmes. Also, biomedical and academic institutions should allocate the adequate and necessary resources to support such and similar investigations which can provide important information to government and non-government institutions to improve health and the medical wellbeing of human and animals. Government and the responsible authorities should enforce appropriate policies, to all veterinary clinics to properly record, document and report animal diseases in their records and to the relevant authorities.

\section{ACKNOWLEDGEMENTS}

All authors are indeed grateful to the personnel's of Alhelal Alazraq veterinary clinic for giving their support throughout this study.

\section{REFERENCES}

[1] Ahmed MO, Daw MA and van Velkinburgh JC. An evolving research culture: Analysis of biomedical publications from Libya, 2003-13. Research Evaluation. 2017; 26(4):284-291

[2] O'Neill DG, Church DB, McGreevy PD, Thomson PC and Brodbelt DC. Prevalence of disorders recorded in cats attending primary-care veterinary practices in England. Veterinary Journal. 2014; 202(2):286-291.

[3] Barde JL, Garba A, Gashua MM, Mohammed MN, Aliyu A, Sa'adatu L, Konzing L, Awulu SJ, Gugong VT and Owada AH. A retrospective study of common diseases of animals in a Private Clinic in Kaduna Metropolitan. Nigerian Veterinary Journal. 2012; 33(3): 557-562.

Int. J. Public Health Sci. Vol. 8, No. 3, Sept 2019: 320-325 
[4] Ahmed MO, Almshawt NF and Elnageh HR. Diarrheagenic Escherichia Coli O157 from Libya: Recent Perspectives and Challenges. Journal of Public Health in Africa. 2017; 4; 8(1):685.

[5] WHO. World Health Organization. 2018. Salmonella (non-typhoidal) www.who.int/mediacentre/factsheets/fs139/en/).

[6] Elnageh HR, Hiblu MA, Abouzeed Y and Ahmed MO. Prevalence and antimicrobial resistance among enteric bacteria and Staphylococcus spp. isolated from pet-companion animals in Tripoli. First International Congress of Biochemistry \& Microbiology Applied Technologies BMAT'2017 3-5 November 2017, www.aeaenvironnement.com/BMAT2017.html

[7] Stull JW, Brophy J and Weese JS. Reducing the risk of pet-associated zoonotic infections. Canadian Medical Association journal. 2015; 14; 187(10):736-43.

[8] Halsby KD, Walsh AL, Campbell C, Hewitt K and Morgan D. Healthy animals, healthy people: zoonosis risk from animal contact in pet shops, a systematic review of the literature. PLoS One. 2014; 26; 9(2):e89309.

[9] Kieffer N, Ahmed MO, Elramalli AK, Daw MA, Poirel L, Álvarez R and Nordmann P. Colistin-resistant carbapenemase-producing isolates among Klebsiella spp. and Acinetobacter baumannii in Tripoli, Libya. Journal of Global Antimicrobial Resistance. 2018; 9; (13):37-39.

[10] Elramalli A, Almshawt N and Ahmed MO. Current problematic and emergence of carbapenemase-producing bacteria: a brief report from a Libyan hospital. Pan African Medical Journal. 2017; 29; 26:180.

[11] Ahmed MO, Aghila E, Elamri S and Baptiste KE. Molecular investigation of carbapenemase-producing Enterobacteriaceae isolated from a Tripoli Hospital, Libya. Libyan Journal of Medical Sciences. 2017; 1:80-82.

[12] Almshawt NF, Hiblu MA and Ahmed MO. Prevalence of antimicrobial resistance of indicator enteric bacteria isolated from cattle in Libya. First International Congress of Biochemistry \& Microbiology Applied Technologies BMAT'2017 3-5 November 2017, www.aea-environnement.com/BMAT2017.html

[13] Kirk MD, Pires SM, Black RE, Caipo M, Crump JA, Devleesschauwer B, Döpfer D, Fazil A, Fischer-Walker CL, Hald T, Hall AJ, Keddy KH, Lake RJ, Lanata CF, Torgerson PR, Havelaar AH and Angulo FJ. World Health Organization Estimates of the Global and Regional Disease Burden of 22 Foodborne Bacterial, Protozoal, and Viral Diseases, 2010: A Data Synthesis. PLoS Medicine. 2015; 3; 12(12):e1001921.

[14] Balcha C, Abdela N. Review of Rabies Preventions and Control. International Journal of Public Health Science. 2017; 6 (4)343 350.

[15] Tadesse G, Tessema TS, Beyene G and Aseffa A. Molecular epidemiology of fluoroquinolone resistant Salmonella in Africa: A systematic review and meta-analysis. PLoS One. 2018; 12; 13(2):e0192575.

[16] Ahmed MO and Baptiste KE. Vancomycin-Resistant Enterococci: A Review of Antimicrobial Resistance Mechanisms and Perspectives of Human and Animal Health. Microbial Drug Resistance. 2018; 24(5):590-606.

[17] Damborg P, Broens EM, Chomel BB, Guenther S, Pasmans F, Wagenaar JA, Weese JS, Wieler LH, Windahl U, Vanrompay D and Guardabassi L. Bacterial Zoonoses Transmitted by Household Pets: State-of-the-Art and Future Perspectives for Targeted Research and Policy Actions. Journal of Comparative Pathology. 2016; 155(1 Suppl 1):S27-40.

[18] Weese JS. Bacterial enteritis in dogs and cats: diagnosis, therapy, and zoonotic potential. The Veterinary clinics of North America. Small animal practice. 2011; 41(2):287-309.

[19] Wedley AL, Dawson S, Maddox TW, Coyne KP, Pinchbeck GL, Clegg P, Nuttall T, Kirchner M and Williams NJ. Carriage of antimicrobial resistant Escherichia coli in dogs: Prevalence, associated risk factors and molecular characteristics. Veterinary Microbiology. 2017; 199:23-30. 